\title{
The blood-brain barrier in primary CNS lymphomas: Ultrastructural evidence of endothelial cell death ${ }^{1}$
}

\author{
Peter P. Molnár, Brian P. O'Neill, Bernd W. Scheithauer, and Dennis R. Groothuis ${ }^{2}$ \\ Department of Neurology, Northwestern University Medical School, Evanston Northwestern Healthcare, \\ Evanston, IL 60201 [P.P.M., D.R.G.]; Present address: Hungarian-Japanese EM Center (HJEMC), \\ Department of Pathology, University Medical School of Debrecen, P. O. Box 24, H-4012 Hungary [P.P.M.]; \\ Department of Neurology [B.P.O.], and Department of Laboratory Medicine and Pathology [B.W.S.], \\ Mayo Clinic and Foundation, Rochester, MN 55905; Department of Neurobiology and Physiology, \\ Northwestern University and the Institute for Neuroscience, Northwestern University,
} Evanston, IL 60201 [D.R.G.]

The vasculature of 24 primary CNS B-cell lymphomas that were not related to acquired immunodeficiency syndrome was systematically studied by electron microscopy. Seven low-grade astrocytic tumors were included for comparison. Classical electron microscopy features of apoptosis were found in lymphoma cells of 21 of 22 subjects. Capillaries of gliomas and lymphomas showed changes reported previously: variability of endothelial cell (EC)-thickness and number, basal lamina thickness and duplication, and fenestrations. Primary CNS B-cell lymphoma ECs showed two distinctive populations of electron-dense and electron-lucent cells. The electron-dense ECs occurred in $38 \%$ of all capillaries, with changes consisting of chromatin condensation in bizarre and contracted nuclei, cytoplasmic shrinkage with markedly increased electron density, and dilatation of the endoplas-

Received 30 July 1998, accepted 11 September 1998.

${ }^{1}$ Dr. Molnár was supported by the Mark Moritz Brain Tumor Research Fellowship; by grants OTKA \# T020128, ETT 330/1996, FKFP 1043/1997, AMFK 707/96, and PFP-4077/1997; by the Soros Foundation; and by Biogal-Teva. This work was also supported by $\mathrm{NIH}$ grant R01-NS12745 and by the Richard M. Lilienfield Memorial Fund.

${ }^{2}$ Address correspondence and reprint requests to Dennis R. Groothuis, M.D., Evanston Northwestern Healthcare, Department of Neurology, 2650 Ridge Avenue, Evanston, IL 60201.

${ }^{3}$ Abbreviations used are as follows: ANOVA, analysis of variance; BBB, blood-brain barrier; EC, endothelial cell; BL, basal lamina; PCNSL, primary CNS lymphoma. mic reticulum. We interpreted these changes as indicative of apoptosis. Cell death eventually resulted in complete disintegration of the endothelium with frank discontinuities of the EC component of the blood-tumor barrier in capillaries and postcapillary venules. Another population of ECs had increased cell volume, conspicuous cytoplasmic electron lucency, dispersed organelles, scattered vesicles, and apical stress fibers. We interpreted these changes as indicative of cellular regeneration. Individual apoptotic ECs often lay next to normal or regenerating ECs. Neither type of EC change was observed in gliomas, which also lacked perivascular neoplastic lymphocytic cuffing. We believe that these populations of ECs, which have not been described in other disorders affecting the bloodbrain barrier, may be induced by cytokines released from necrotic and/or apoptotic tumor lymphocytes and may explain the unusual imaging characteristics of primary CNS B-cell lymphomas treated with corticosteroids. Neuro-Oncology 1, 89-100, 1999 (Posted to NeuroOncology [serial online], Doc. 98-09, April 30, 1999. $U R L<$ neuro-oncology.mc.duke.edu>)

$\Lambda$ lthough much is known about the pathobiology of PCNSLs, ${ }^{3}$ they present a therapeutic challenge to neuro-oncologists who note a rising incidence of this once uncommon tumor (Corn et al., 1997; Grant and Isaacson, 1992; Morgello, 1995; Neuwelt et al., 1990), particularly in HIV-infected individuals (Tellez et al., 1997). When treated with corticosteroid therapy, PCNSLs will sometimes show a rapid, partial to com- 
plete disappearance of their dense, typically homogenous contrast enhancement. This response, which has been termed the "ghost tumor" phenomenon (Vaquero et al., 1984), has been studied both clinically and by quantitative measurement of BBB function (Ott et al., 1991; Pirotte et al., 1997); the frequency with which this effect occurs, the time course of its development, and the quantitative magnitude of the change have not been studied, in part because of the rarity of this tumor. This peculiarity of contrast medium uptake suggests that, in either anatomic and/or physiologic terms, the BBB in PCNSLs differs from that of other brain tumors.

Imaging studies have shown that PCNSLs may be quite variable, but these studies have not provided information that clarifies the ghost tumor phenomenon. At the one extreme, PCNSL may appear as a nonenhancing lesion on CT or MRI (DeAngelis, 1993) and generally appear avascular by angiography (Kobayashi et al., 1983). More commonly, PCNSL enhances densely and homogeneously with contrast-enhanced CT or MRI (Ueda et al., 1995). Blood flow to PCNSL is comparable to that of gray matter (Plowman and Wise, 1984; Ueda et al., 1995), and PET, combined with histological examination suggests a rich microvasculature with breakdown of the BBB (Plowman and Wise, 1984), but does not suggest the basis for the altered BBB. Microscopically, PCNSLs lack vascular or endothelial proliferation (Burger and Scheithauer, 1994), which suggests that the basis for the abnormal permeability resides in altered capillary structure. The two ultrastructural studies of PCNSL capillaries published to date have reported morphological changes similar to those in other malignant brain tumors (Hirano et al., 1974; Ochi et al., 1989), but nothing distinctive to explain the ghost tumor phenomenon. Motivated by a desire to explain the ghost tumor phenomenon, we systematically examined the ultrastructure of ECs from tumor specimens of PCNSL patients at the Mayo Clinic, which represents a retrospective study of a diverse population.

Table 1. Clinicopathologic data from primary CNS lymphoma subjects

\begin{tabular}{|c|c|c|c|c|c|c|c|c|}
\hline Subject & $\begin{array}{l}\text { Age } \\
\text { (years) }\end{array}$ & Sex & Pathology $y^{a}$ & $\begin{array}{l}\text { Type of } \\
\text { surgery }\end{array}$ & Steroids ${ }^{b}$ & $\begin{array}{l}\text { Apoptotic } \\
\text { tumor cells? }^{c}\end{array}$ & $\begin{array}{l}\text { No. of capillaries } \\
\text { studied }\end{array}$ & $\begin{array}{c}\text { No. of capillaries } \\
\text { with apoptotic ECs }\end{array}$ \\
\hline 1 & 78 & $M$ & DLC & C & $Y$ & $\mathrm{~N}$ & 2 & 0 \\
\hline 2 & 81 & $M$ & DLC & B & $Y$ & $Y$ & 11 & 1 \\
\hline 3 & 68 & $M$ & DLC & B & $\mathrm{N}$ & $Y$ & 8 & 4 \\
\hline 4 & 43 & $M$ & DLC & B & $Y$ & $\mathrm{~N}$ & 8 & 1 \\
\hline 5 & 59 & $\mathrm{~F}$ & DLC & B & $Y$ & $Y$ & 4 & 1 \\
\hline 6 & 68 & $M$ & DLC & $C$ & $\mathrm{~N}$ & $Y$ & 2 & 1 \\
\hline 7 & 30 & $M$ & DLC & C & $Y$ & $Y$ & 1 & 1 \\
\hline 8 & 48 & $M$ & DLC & C & $Y$ & $Y$ & 0 & 0 \\
\hline 9 & 38 & $M$ & DLC & B & $Y$ & $Y$ & 15 & 1 \\
\hline 10 & 53 & $M$ & DLC & $C$ & $\mathrm{~N}$ & $Y$ & 1 & 1 \\
\hline 11 & 63 & $M$ & DLC & B & $Y$ & $Y$ & 22 & 13 \\
\hline 12 & 71 & $M$ & DLC & B & $Y$ & $Y$ & 7 & 1 \\
\hline 13 & 43 & $\mathrm{~F}$ & DLC & B & $Y$ & $Y$ & 11 & 2 \\
\hline 14 & 14 & $M$ & DLC & B & $\mathrm{N}$ & $Y$ & 13 & 13 \\
\hline 15 & 54 & $\mathrm{~F}$ & DLC & $C$ & $Y$ & $\mathrm{~N}$ & 8 & 0 \\
\hline 16 & 61 & $M$ & DLC & B & $Y$ & $Y$ & 6 & 3 \\
\hline 17 & 53 & $M$ & DLC & B & $\mathrm{N}$ & $Y$ & 14 & 2 \\
\hline 18 & 61 & $\mathrm{~F}$ & $\mathrm{DMC}$ & $C$ & $\mathrm{~N}$ & $Y$ & 8 & 3 \\
\hline 19 & 58 & $F$ & $\mathrm{DMC}$ & $C$ & $Y$ & $Y$ & 3 & 1 \\
\hline 20 & 75 & $F$ & $\mathrm{DMC}$ & B & $Y$ & $Y$ & 1 & 1 \\
\hline 21 & 58 & $F$ & DMC & C & $\mathrm{Y}$ & $Y$ & 5 & 3 \\
\hline 22 & 68 & $\mathrm{~F}$ & $\mathrm{DMC}$ & C & $\mathrm{Y}$ & $Y$ & 34 & 14 \\
\hline 23 & 58 & $M$ & $\mathrm{DMC}$ & B & $\mathrm{N}$ & $Y$ & 32 & 7 \\
\hline 24 & 52 & $M$ & $\mathrm{DMC}$ & B & $\mathrm{Y}$ & $Y$ & 18 & 16 \\
\hline Summary & $\begin{array}{l}56.4^{ \pm} \\
15.4^{d}\end{array}$ & $\begin{array}{c}8 \mathrm{~F} \\
16 \mathrm{M}\end{array}$ & $\begin{array}{l}\text { 17DLC } \\
\text { 7DMC }\end{array}$ & $\begin{array}{l}10 C \\
14 B\end{array}$ & $\begin{array}{l}7 \mathrm{~N} \\
17 \mathrm{Y}\end{array}$ & $\begin{array}{l}3 N \\
21 Y\end{array}$ & $\begin{array}{c}n=234^{\mathrm{e}} \\
9.8 \pm 9.2^{\mathrm{d}}\end{array}$ & $\begin{array}{l}n=90^{\mathrm{e}} \\
38 \%^{\mathrm{f}}\end{array}$ \\
\hline
\end{tabular}

B, stereotaxic biopsy; C, craniotomy; DLC, diffuse large cell; DMC, diffuse mixed cell; ECs, endothelial cells; $F$, female; $M$, male.

aPathology of B-cell lymphoma.

${ }^{b} Y$, steroids were received prior to surgery; $\mathrm{N}$, no steroids were received prior to surgery.

${ }^{\top} \mathrm{Y}$, apoptotic tumor cells were observed; $\mathrm{N}$, no apoptotic tumor cells were observed.

${ }^{\mathrm{d}}$ Mean \pm SD.

${ }^{\mathrm{e}}$ Total number of capillaries studied.

${ }^{f}$ Frequency of capillaries containing apoptotic endothelial cells. 


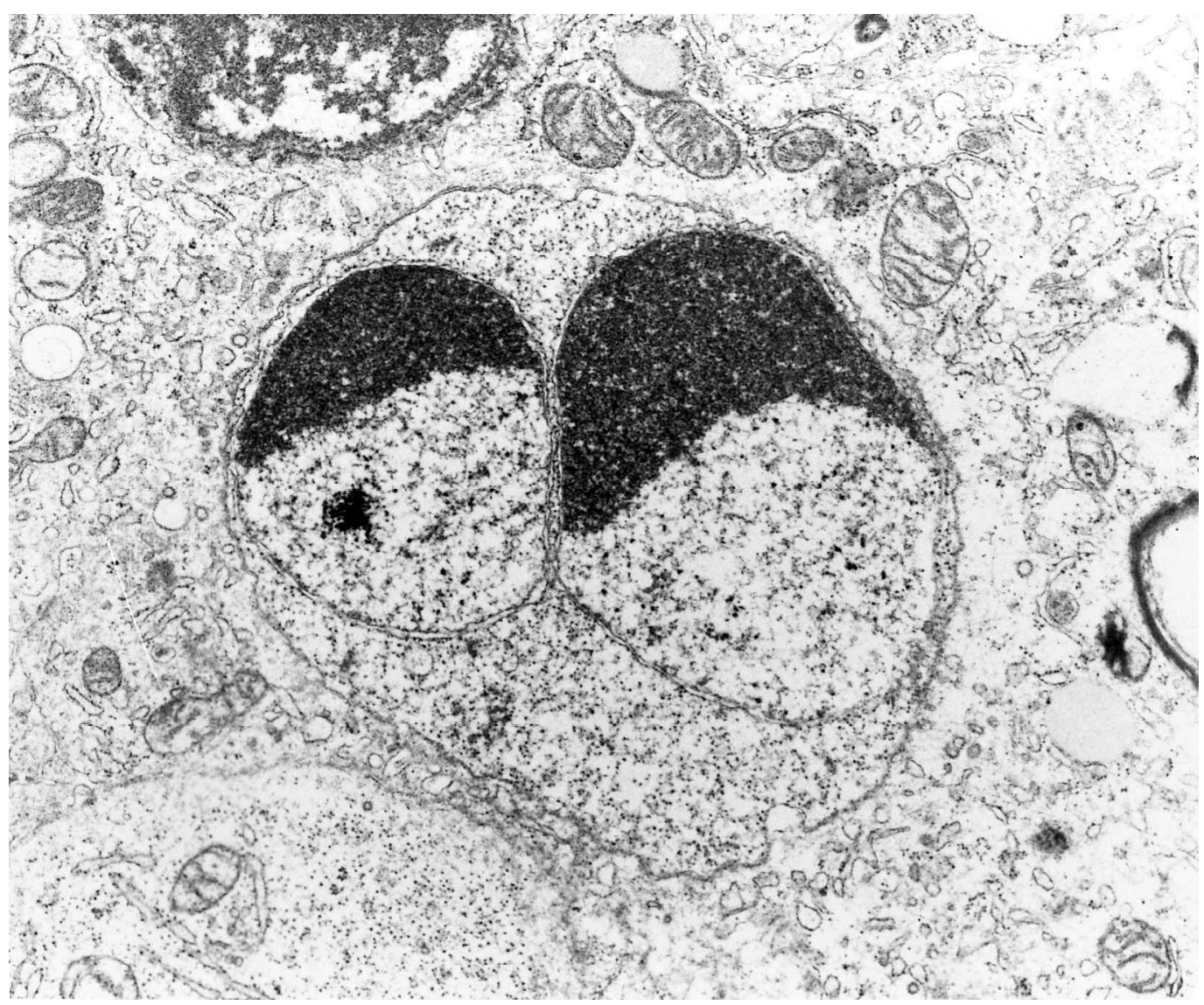

Fig. 1. Apoptotic lymphoma cell. Classic crescentic, peripheral chromatin condensation in an apoptotic lymphoma cell. The widened intercellular space contains flocculent material. Adjacent myelin figures indicate damage to the neurophil due to tumor infiltration. A nonapoptotic tumor cell (lower left) and remnants of a necrotic cell (upper left) are also visible $(\times 16,000)$.

\section{Materials and Methods}

In 1995, Tomlinson et al. reported the clinicopathologic features of 89 patients with PCNSL. From 24 of those patients, 24 tumors were included in this study and some of their characteristics are presented in Table 1 . None of the patients had a history of organ transplantation, blood transfusion, drug abuse, or acquired immunodeficiency syndrome. Tumor tissue was fixed in Trump's solution (1\% glutaraldehyde and 4\% formaldehyde) at $\mathrm{pH} 7.2$ and routinely processed for electron microscopy. All 1$\mathrm{mm}$-thick sections selected for study contained perivascular tumor infiltrates varying from scant to dense accumulations. The frequency of tumor cell death, particularly apoptosis, was systematically recorded. To minimize sampling error, every capillary and postcapillary venule in each electron microscopic section was photographed at the same magnification. Table 1 shows the number of capillaries studied per case, as well as the number of capillaries with changes interpreted as apoptosis. Since morphologic indications of cell activation, oncosis, and necrosis often formed a continuum with overlapping features, no attempt was made to quantitate them. As a control group, representing another histopathologic category of brain tumors in which endothelial proliferation is not prominent, and as a con- trol for evaluating tissue fixation, 5 pilocytic astrocytomas (World Health Organization grade I) and 2 grade II fibrillary astrocytomas were included. ANOVA was used to examine the significance of the parameters and their interactions.

\section{Results}

\section{Clinical Features}

The patient population from which the specimens were drawn was quite heterogeneous. Although 10 of the patients underwent a craniotomy, the tumors of this group contained fewer capillaries $(n=64)$ than those of the biopsy group $(n=170)$. Two of the biopsies had no tumor cells (subjects 1 and 15). Seven of the subjects were not on steroids when the specimens were acquired, whereas 17 were receiving steroids, although the dose, frequency, chronicity, and type of steroid varied from one subject to the next. None of the variables in Table 1 (age, sex, pathology, type of surgery, or use of steroids) was statistically associated with the occurrence of apoptosis in ECs $(P>0.1$, ANOVA). The frequency of apoptotic ECs was the same whether steroids were used, whether the tumors were diffuse large cell or diffuse mixed cell, or whether the subjects were male or female. 


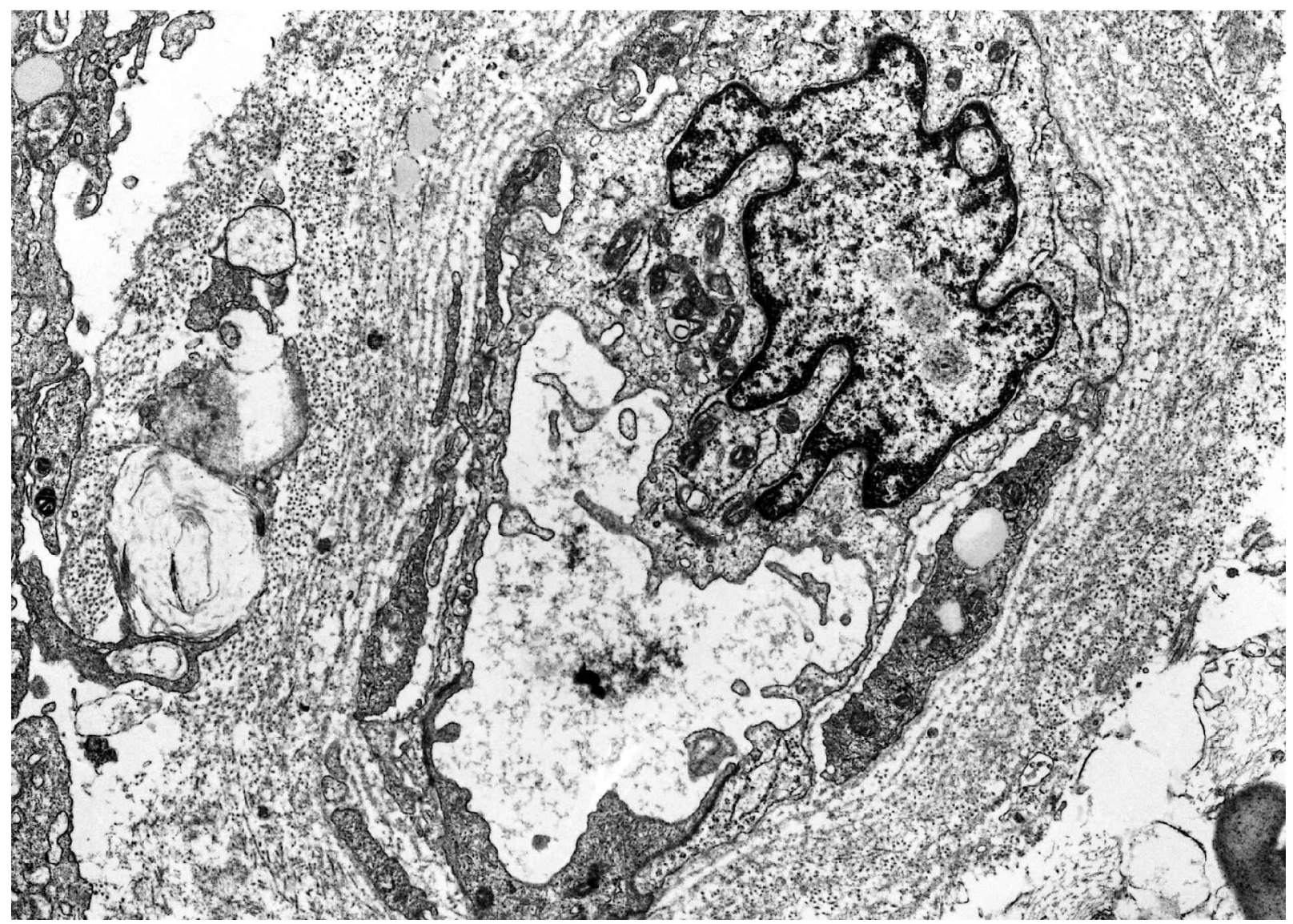

Fig. 2. Lymphoma capillary with proliferating basal lamina. The basal lamina ensheathes elongated, dense pericytic processes. The endothelium is multilayered. The width and cytoplasmic density of individual endothelial cells are highly variable. The lumen contains cytoplasmic fragments sloughed from the luminal surface. Intercellular junctions between endothelial cells vary in length, being either dark and elongate on both sides of the endothelial cell (bottom) or open (upper left side). One tangentially cut endothelial cell nucleus shows a tortuous nuclear membrane with peripheral condensation of chromatin. A few cytoplasmic vacuoles and Weibel-Palade bodies are present $(\times 16,000)$.

\section{Morphology of Tumor Cells}

The general ultrastructural features of lymphoma and glioma cells are the subject of numerous previous publications (Burger and Scheithauer, 1994; Cheville, 1994). In 21 of the 24 tumors we studied $(88 \%)$, the lymphoma cells exhibited classic features of apoptosis (Fig. 1) (Cummings et al., 1997; Kaufmann, 1997; Majno and Joris, 1995; Schulte-Herman et al., 1997; Trump et al., 1997; Wyllie, 1997); 2 of the other 3 specimens did not contain lymphoma cells. Necrotic lymphoma cells were also rather common, both adjacent to and remote from capillaries. Disintegrating neoplastic lymphocytes frequently lay in contact with pericytes and/or ECs. Apoptosis was not seen in the glioma specimens.

\section{Morphology of Capillary Endothelium: Nonspecific Changes}

A total of 234 capillaries was analyzed from the 24 PCNSL specimens (Table 1). The variable number per case was directly related to the number of blocks prepared for electron microscopy, and not to the type of surgery. In semithin sections, vessels were seen as randomly oriented vascular profiles. ECs, some of which were relatively normal, exhibited the ultrastructural spectrum of nonspecific abnormalities known to occur in capillaries of primary and metastatic CNS tumors (Bertossi et al., 1997; Shibata, 1989), which were observed in both the gliomas and lymphomas in our study sample. These included marked irregularity of lumen size, with blebs and vesicles being either partially attached or free-floating in flocculent material containing cell debris. Individual or aggregated and partly or totally degranulated platelets were frequently attached to the luminal surface (Fig. 2). Intercellular junctions varied markedly in length, width, and density, but appeared competent. Cytoplasm varied greatly in width and attenuated areas with fenestrations sometimes tapered abruptly or alternated with broad full cell bodies (Fig. 2); fenestrations were not uncommon (Fig. 3). Isolated pinocytotic vesicles were relatively abundant. Excessive cytoplasmic vacuolization was frequently seen without formation of transmural channels or vesiculo-vacuolar organelles. Basal plasmalemmal vesicles were less numerous and were usually disoriented relative to the abluminal surface. Mitochondria of various sizes, shapes, and numbers lay scattered in the finely granular cytoplasm, which was also rich in filaments and ribosomes. Tortuosity, thickening, disruption, and reduplication of $\mathrm{BL}$ was 


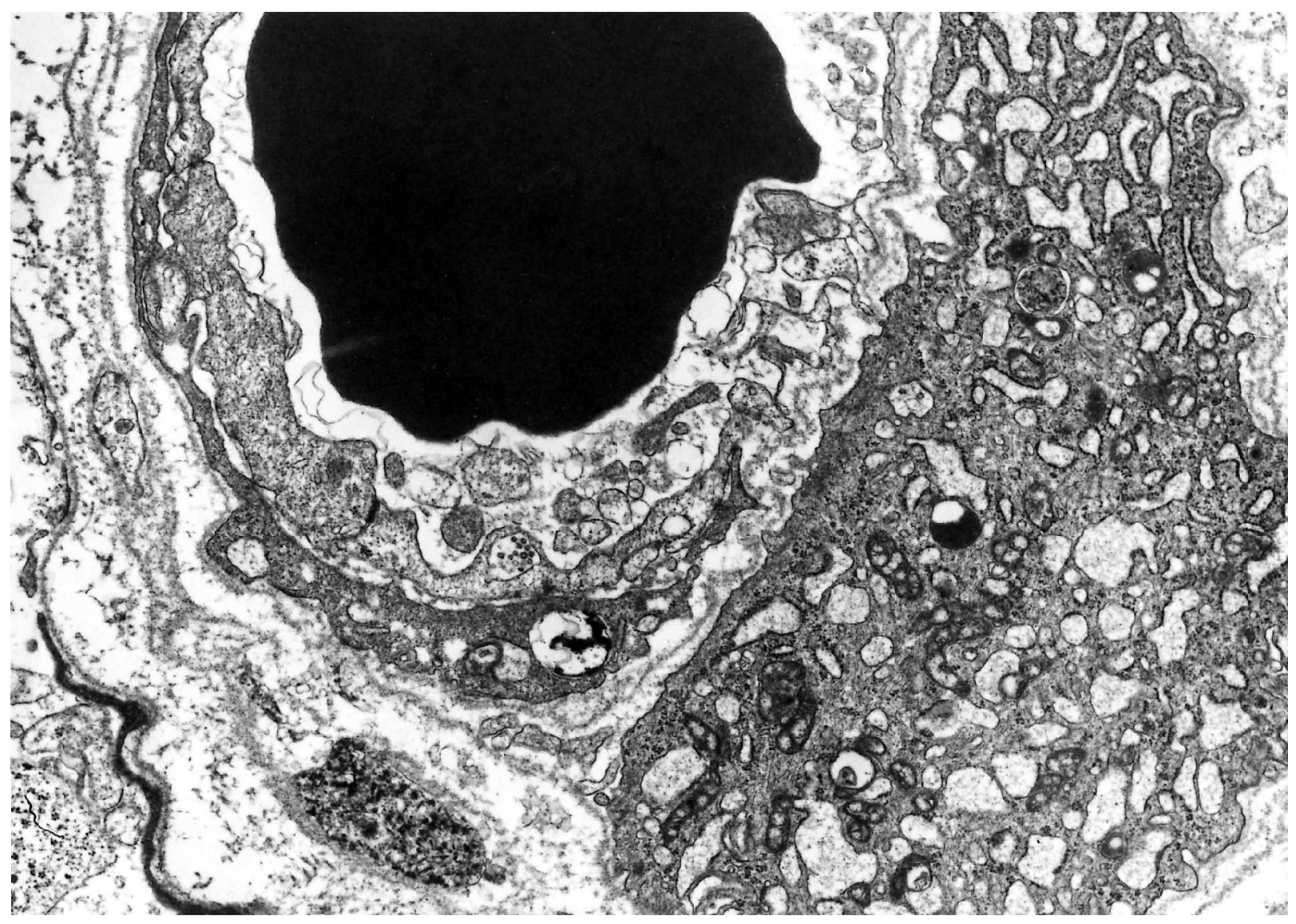

Fig. 3. Lymphoma capillary with irregular, multilayered, and fenestrated endothelium. A red blood cell resides in the lumen of a capillary surrounded by numerous endothelial cell fragments. Junctions are short and partially dilated. Vacuolization, cytoskeletal fibers, and the occasional multivesicular body are seen within various endothelial cells. There is marked luminal bleb formation. Note extensive labyrinthine transformation of rough endoplasmic reticulum in a pericyte (right). This is the same type of cytoplasmic change shown in endothelial cells in Figs. 6 and 7. The perivascular space is widened, edematous, and contains some necrotic debris $(\times 16,000)$.

conspicuous (Figs. 2 and 4). Pericytes were present in many cases and were mostly ensheathed by an irregular BL (Fig. 4). These changes were also observed in the ECs of the gliomas.

\section{Morphology of Capillary Endothelium: Changes Specific to Primary CNS Lymphoma}

The most striking ultrastructural change observed in the ECs of lymphoma capillaries, which was not found in the gliomas, was a marked variation in cytoplasmic electron density (Figs. 5-8). This varied from electron-lucent or light ECs to ones that were electron dense or dark. In most cases, the light ECs were vacuolated and tall cuboidal to columnar cells (Figs. 5 and 6), while the dark ECs were usually low, flat, structureless, and often fragmented (Figs. 3-6 and 8). In some cases, elevated tombstone-shaped ECs were also found (Fig. 6). Although junctions between these various ECs were sometimes obscured, close connections between both abnormal and more normal appearing ECs were usually maintained. The light ECs were frequently swollen with increased surface area, usually lacking nuclear profiles and containing both dense bodies as well as dilated vacuoles (Figs. 5 and 6). In areas with more than one layer of ECs, dark basal cells were sometimes covered by rarefied light cells (Fig. 6). Both nuclear and cytoplasmic changes were conspicuous (Figs. 3-8). In some dark cells, the nucleus was markedly convoluted and hypertrophic with conspicuous margination of chromatin (Figs. 5 and 8). In others, the nuclear lobulation was more prominent and accompanied by nuclear condensation and shrinkage (Figs. 6 and 7). The endoplasmic reticulum was often dilated, with a complex labyrinthine vacuolation of the cytoplasm (Figs. 3, 7, and 8). Mitochondria appeared intact in the presence of cytoplasmic shrinkage that obscured the fine structure of other organelles (Fig. 7). In some areas, there was a loss of the continuous endothelial layer (Fig. 8), exposing the often reduplicated (Figs. 2 and 4) and frequently frayed BL (Fig. 8). The blood vessels of the lymphomas were frequently cuffed by tumor cells, many of which showed signs of apoptosis. Pericytes were often in intimate contact with the reduplicated or discontinuous BL (Figs. 3 and 4) and ECs frequently had no direct contact with normal astrocytic processes or neuropil or extracellular matrix. The pericytes interposed between lymphoma cells and the variously altered ECs quite often showed the same changes described in ECs (Fig. 3). In some cases, the exact nature of cells on the abluminal side of the BL was difficult to determine. 


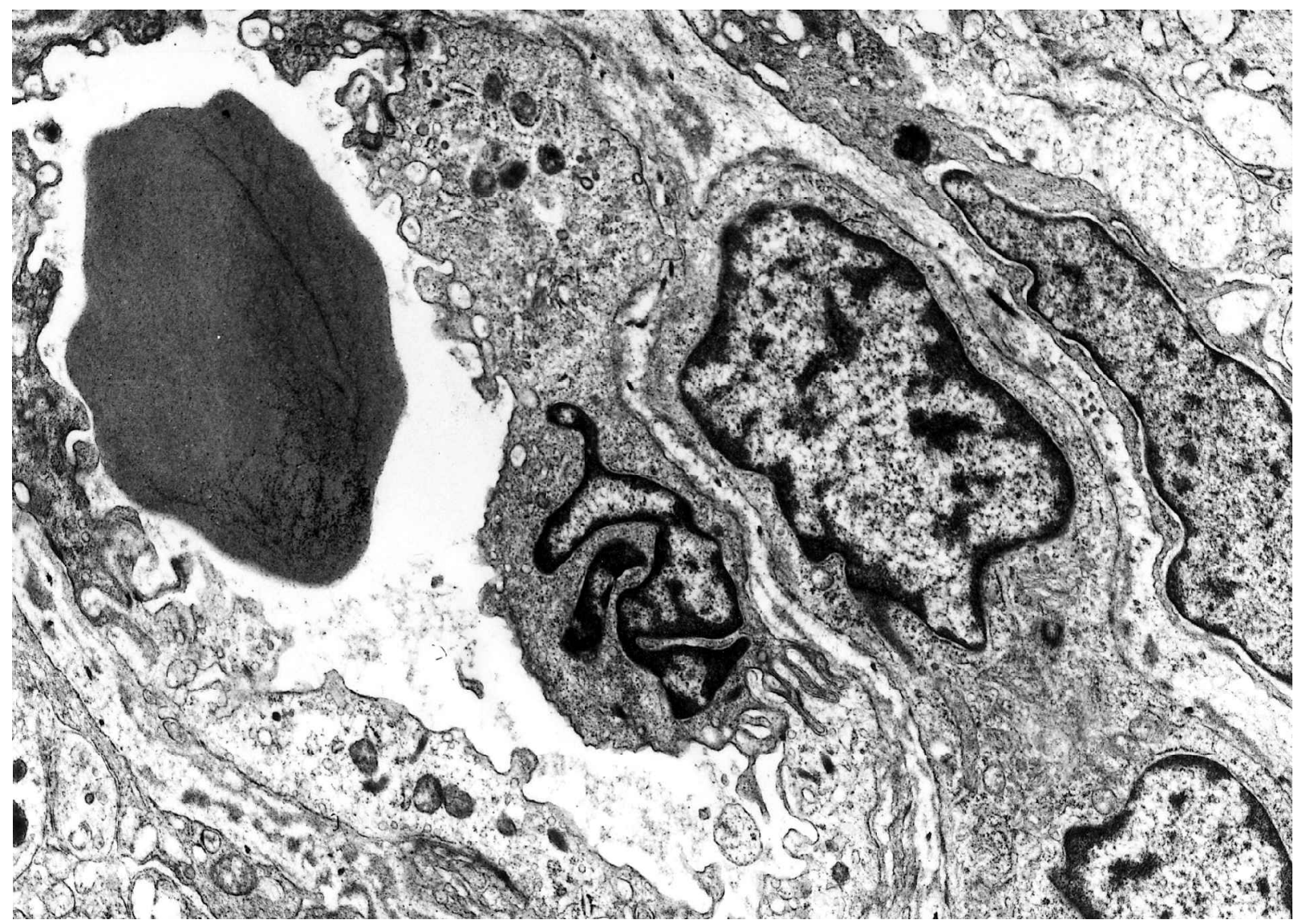

Fig. 4. Lymphoma capillary. The capillary has a red blood cell in its lumen. The endothelium varies in thickness; adjacent light and dark endothelial cells are visible. The convoluted endothelial cell nucleus (center) indicates early apoptotic change. The cytoplasm of the light endothelial cell on the lower left is vacuolated and contains some dense bodies and forms an abluminal hemidesmosome. Other endothelial cells are vacuolated and show bleb formation. Junctions between endothelial cells are either short and dark or elongate and tortuous. Two nearly normal pericytes and part of a microglial cell are seen outside the capillary on the right $(\times 16,000)$.

\section{Discussion}

We focused on the capillary endothelium in PCNSLs to search for ultrastructural changes that would explain the unusual imaging properties of these tumors, that is, the ghost tumor phenomenon (Grant and Isaacson, 1992; Neuwelt et al., 1990; Ott et al., 1991; Pirotte et al., 1997; Vaquero et al., 1984). We found obvious structural changes that explained the increased permeability so frequently seen in these tumors, although we were unable to establish with certainty that these changes are responsible for the ghost tumor phenomenon. Endothelial cells were frequently thinned (Figs. 3-8), contained fenestrations (Fig. 3), and in many instances had no endothelial cell between the capillary lumen and the underlying basement membrane, causing frank endothelial discontinuities (Fig. 8). These ultrastructural changes explain the dense contrast enhancement seen in many PCNSLs.

Research into the process of cell death is currently undergoing an explosion of information, and the exact genetic, biochemical, and morphological pathways that cells follow on their course to death are not yet clearly understood or defined. In our discussion, we use the outline of cell death described by Majno and Joris (1995), who distinguish between two major pathways: apoptosis and oncosis. They state that the term "necrosis" refers to changes secondary to cell death by any mechanism, that is, necrotic cells are a corps of cells that have been killed by any of several different insults. They describe apoptosis as a complex process, characterized by both morphologic and biochemical criteria. Morphologically, the cell shrinks and becomes electron-dense with margination of chromatin, which has curved profiles, and with little or no swelling of the mitochondria or other organelles, all of which typically occur very rapidly, that is, in minutes. Oncosis is typified by ischemic cell death and is characterized morphologically by cellular swelling over a time period of hours. The swelling is related to ionic fluxes, may include cellular organelles, and is followed by cytoplasmic or organelle vacuolization, blebbing, and increased membrane permeability, all of which are manifested ultrastructurally by increased cellular and organelle size and electron lucency.

Apoptotic cell death frequently occurs in lymphomas (Pirotte et al., 1997; Vaquero et al., 1984) and was present in 21 of 22 lymphomas in our series (Fig. 1). Apoptosis in lymphoma cells is regulated by bcl-2 and p53 gene products (Cory, 1995; Piris et al., 1994) and is induced by corticosteroids (Distelhorst and Dubyak, 


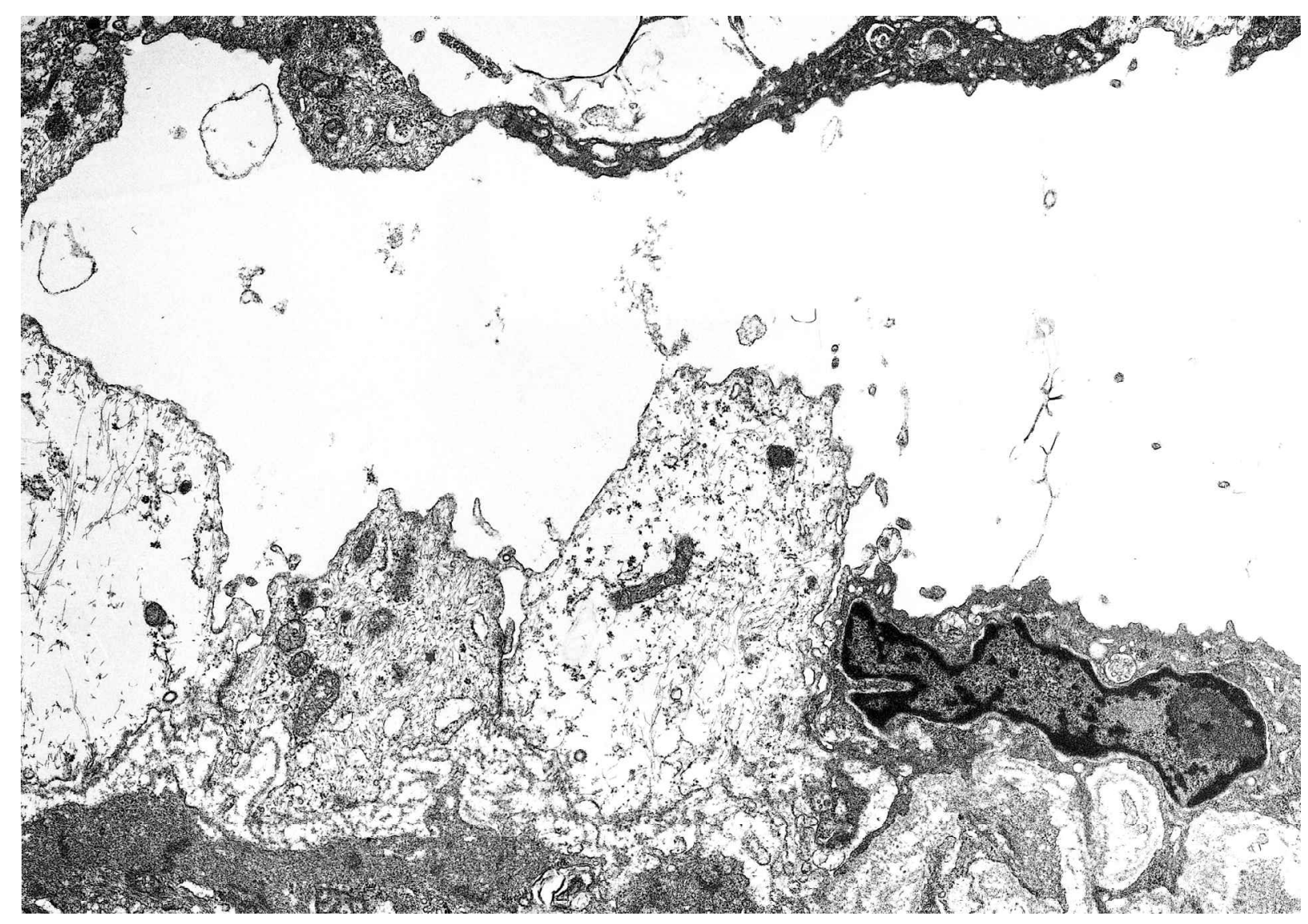

Fig. 5. Longitudinal section of a lymphoma capillary or postcapillary venule. On the top, thin, dark endothelial cells contain vacuoles, an almost intact cytoskeleton, and mildly damaged mitochondria. Three tall, electron-lucent endothelial cells on the bottom right exhibit cytoplasmic stress fibers, vacuoles, and seemingly intact, relatively short junctions. A para-apoptotic endothelial cell (lower right) contains an intracytoplasmic multivesicular body and somewhat dilated rough endoplasmic reticulum. Freely floating blebs and cellular debris are seen in the lumen. The basal lamina is reduplicated, frayed, and fragmented. Increased electron density of a pericyte (bottom) indicates para-apoptosis $(\times 16,000)$.

1998). Apoptosis was common in the lymphoma cells in our series, regardless of whether the patients were on steroids (Table 1).

Ultrastructural changes that we interpret as apoptosis were present in $38 \%$ of the capillaries from our material (Table 1). Hirano et al. (1974) mentioned variable, sometimes increased, electron density of ECs in a single case of PCNSL, but did not identify it as a distinct phenomenon. We observed ultrastructural changes that have not been described in ECs of other brain tumors, which we believe represent a continuum and which suggest to us that the ECs in the PCNSLs were in a dynamic state of death and regeneration. A review of all photomicrographs suggested that normal ECs represented the midpoint of a spectrum from which cells either tended toward increased volume and cytoplasmic lucency (resulting in light cells) or toward shrinkage, darkening, and disintegration (resulting in dark cells). Adjacent cells sometimes seemed to have followed opposite paths, toward either light or dark cells (Figs. 5 and 6). Cells with transitional features were seen (Fig. 5). In those cells that eventually became irregular, flattened, or globular and homogeneously dark (Fig. 8), conspicuous nuclear and cytoplasmic changes occurred (Figs. 3-8). In some, the nucleus first became markedly convoluted and hypertrophic with conspicuous margination of chromatin
(Figs. 2 and 8), followed by increasing nuclear lobulation, condensation, and shrinkage (Figs. 4, 5, and 6). In other cells, the cytoplasmic changes preceded nuclear alterations. Since nuclear profiles were not always in the plane of section, the sequence of nuclear and cytoplasmic changes was difficult to establish. After nuclear and cytoplasmic shrinkage, "mummification" finally resulted in loss of the continuous endothelial layer, exposing the BL (Fig. 8). Although apoptosis may be seen in the tumor cells of gliomas, the sequence of ultrastructural changes that we interpret as apoptosis was not seen in the ECs of the seven astrocytomas that we included as controls, nor have we seen such changes in our experience with electron microscopic samples of ECs from normal brain, other brain tumors, or other brain diseases. Apoptosis has not been reported in electron microscopic studies of the ECs from glioblastoma multiforme (Rojiani and Dorovini-Zis, 1996; Roy and Sarkar, 1989). However, some of the EC changes observed in our study correspond to apoptosis, many resembling so-called "nonclassical" or "para-apoptosis" (Asher, 1995). Some of the ECs looked like the dark mummy or tombstone cells described in association with Hodgkin's disease (Benharroch et al., 1996; Lorenzen et al., 1997). Such variation in cell morphology in the same cell population is common; indeed, it can even be seen 


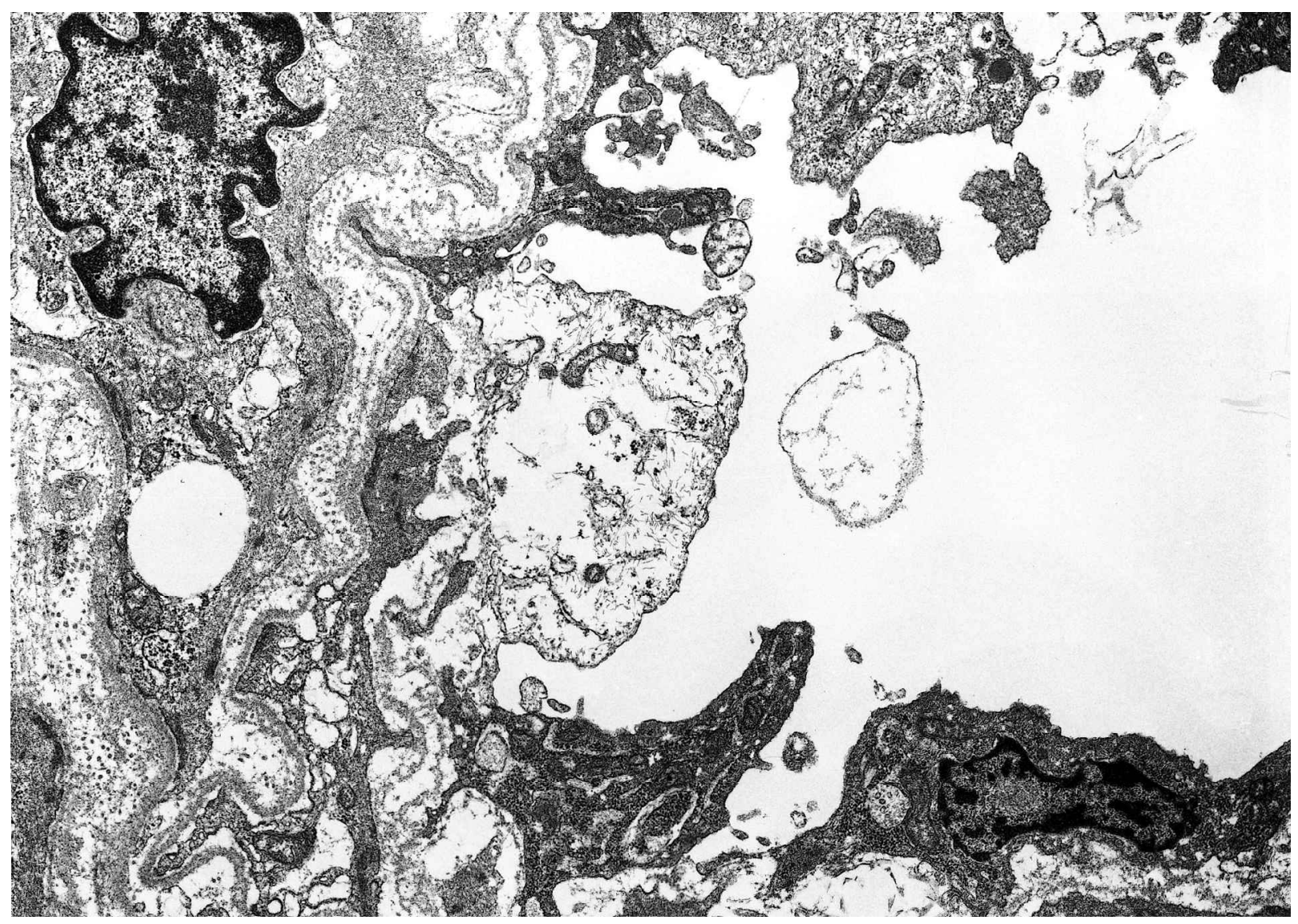

Fig. 6. Lymphoma capillary with variation in endothelial cell height and cytoplasmic electron density. One endothelial cell (lower right corner) is flat and exhibits an elongate nucleus, marginated chromatin, and dark cytoplasm (early apoptosis) containing a multivesicular body. Two conical, dark ("tombstone," "mummy," or para-apoptotic) endothelial cells flank a cuboidal, light endothelial cell (center). The "washed-out" cytoplasm of the latter contains a few apical stress fibers and scattered mitochondria. The larger dark endothelial cell (bottom center) shows dilatation of its rough endoplasmic reticulum. The cytoplasm of the endothelial cell on top is of intermediate density and contains a lysosome as well as mitochondria with fuzzy internal structure. The basal lamina is multilayered, and a dark cell process of a possibly apoptotic endothelial cell is seen attached to it. The lumen contains cell fragments and blebs. A pericyte (upper left) appears intact $(\times 16,000)$.

within different nuclei of the same multinucleated giant cell (Honma and Hamasaki, 1996).

In contrast, we did not find evidence that ECs were undergoing oncosis, although in our study many of the abnormal ECs were of the electron-lucent variety (Figs. 6-8). Electron lucency of ECs has been considered by some to be reactive in nature, suggesting an activated state of either hypertrophy or regeneration, which is sometimes called "functional cellular edema" and is often accompanied by an increase of cell volume. Some authors believe that these changes may indicate EC regeneration, a process in which platelets and their products play an essential role. The enlarged cuboidal washed-out light cells in the PCNSLs (Figs. 6-8) bear a striking resemblance to the ECs described in a series of papers about EC regeneration (Haudenschild and Schwartz, 1979; Reidy and Schwartz, 1981, 1983; Schwartz et al., 1978). In many instances, electron-lucent cells overlaid electron-dense ECs, suggesting that regeneration and replacement were occurring simultaneously (Fig. 7). Increased electron lucency, presumably due to activation of capillary ECs and pericytes and accompanied by an increase in abluminal endocytosis, has been observed in peritumoral regions of anaplastic gliomas (Bertossi et al., 1997).

Our study is morphologic and descriptive. On that basis alone, the ECs of PCNSLs are distinctive and are different from the ECs of other brain tumors. Our interpretation about the mechanism of cell death is speculative. We suggest that a significant population of the ECs were undergoing apoptotic or para-apoptotic cell death (Asher, 1995), while another subpopulation of the ECs was regenerating in an attempt to maintain microvascular integrity. In this retrospective study, we did not look for biochemical or molecular markers of apoptosis. Current research efforts are trying to integrate the biochemical, molecular and morphological underpinnings of apoptosis (Bellamy et al., 1995; Benharroch et al., 1996; Collins et al., 1997; Lo et al., 1995; Madigan and Penfold, 1997; Negri et al., 1997; Pistoia, 1997; Regan et al., 1995; Savill, 1994; Sgonc and Wick, 1994; Tsai et al., 1996). Perhaps these can be applied to future studies of ECs in PCNSLs.

There is ample evidence to support major differences in the tumor microenvironment between gliomas and PCNSLs and, therefore, in the microenvironment of the 


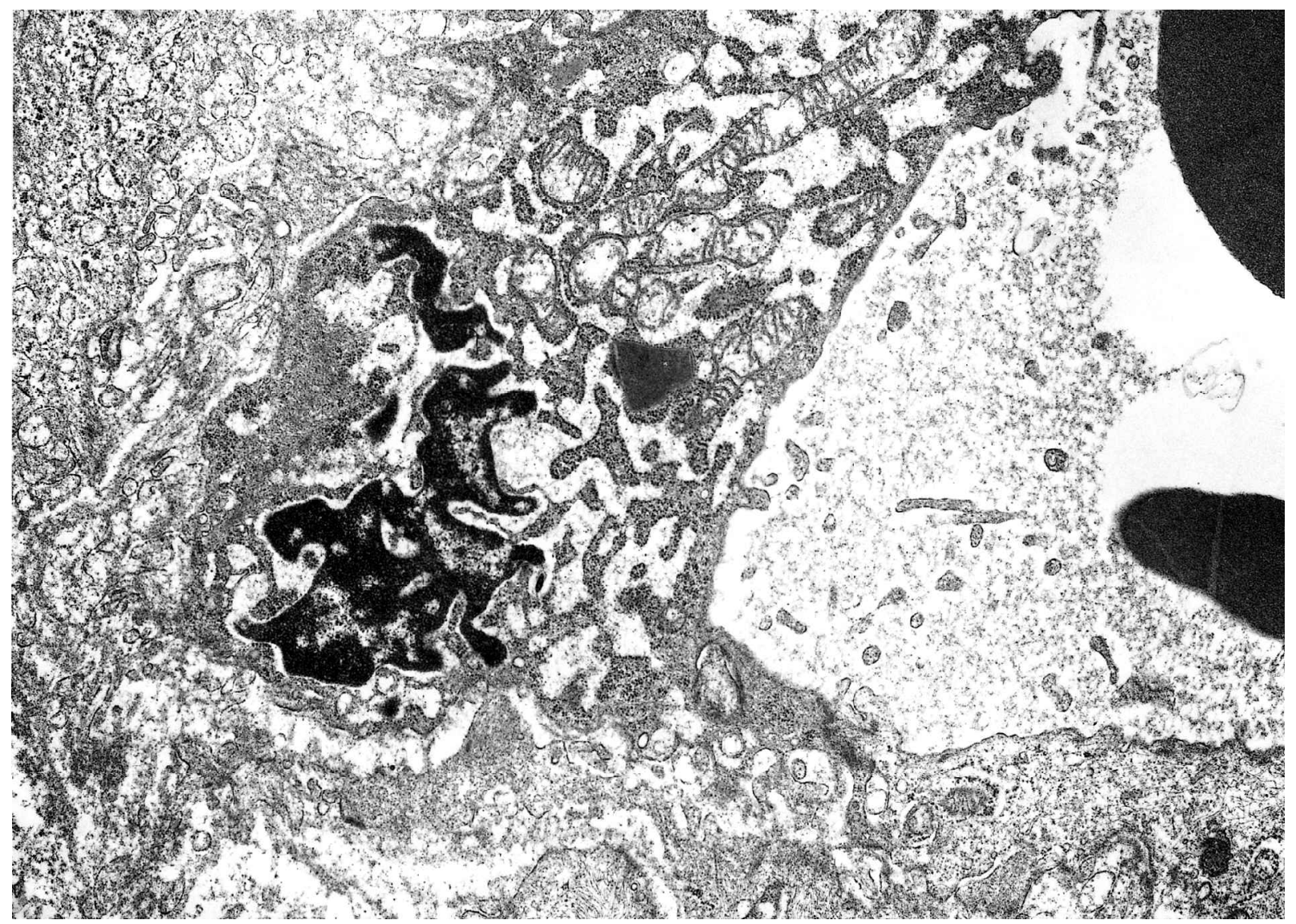

Fig. 7. Apoptosis in a tangentially cut endothelial cell of primary CNS lymphoma. Advanced nuclear shrinkage, lobulation, and chromatin condensation is accompanied by labyrinthine dilatation of rough endoplasmic reticulum and dilation of the perinuclear cistern. Mitochondria are intact, but a junction with the adjacent light endothelial cell (lower right) is obliterated. The lumen contains fragments of detached villous cytoplasmic projections and fragments of two red blood cells $(\times 16,000)$.

tumor microvasculature. As mentioned earlier, apoptosis in lymphomas is closely regulated by bcl- 2 and p 53 proteins, a rather delicate system that may be influenced by both extrinsic and intrinsic factors (Cummings et al., 1997; Kaufmann, 1997; Schulte-Herman et al., 1997; Trump et al., 1997; Wyllie, 1997). Although T-cell infiltrates, which are recognized as a source of cytotoxic cytokines, are regular features of most primary B-cell PCNSLs (Bashir et al., 1996), B cells are also capable of releasing a host of cytokines and chemokines, including TNF- $\alpha$ (Pistoia, 1997; Tsai et al., 1996). TNF- $\alpha$ (tumor necrosis factor- $\alpha$ ) can activate at least two separate pathways of EC injury (Slowik et al., 1997) and may interact with the metabolism of IL-1 (interleukin-1), which itself is capable of inducing major phenotypic changes in endothelium (Romero et al., 1997). In addition, TNF- $\alpha$ has an angiogenic effect (Polunovsky et al., 1994) and may act as a survival factor in transformed EC lines (Maier et al., 1996). It is interesting to speculate that dying $\mathrm{B}$ cells plus the paracrine effector molecules released by pericytes, microglia, and $\mathrm{T}$ cells concertedly bring about the EC changes we observed in PCNSLs (Bashir et al., 1996; Mantovani et al., 1997; Merrill and Benveniste, 1996; Pistoia, 1997; Tsai et al., 1996). It is not surprising that endothelial cell death occurs in vari- ous morphological forms, including both oncosis and apoptosis (Crisby et al., 1997). The threshold of toxic effects, and thus the final outcome, is determined not only by the cytotoxic damage done, but also by the overall cellular milieu (Clarke, 1990; Crisby et al., 1997; Kahaleh et al., 1988; Portera-Cailliau et al., 1997; Schwartz, 1995). Madigan and Penfold (1997) reviewed the means by which pericapillary cells and various mononuclear phagocytes modify EC ultrastructure and affect the normal barrier properties of vessels in retinoblastoma. Our study represents yet another example of a unique microenvironment, one that provides close interaction of tumor and pericapillary/capillary cells.

Although we were unable to explain the ghost tumor phenomenon, our study did provide us with insight into the problem. First, there are many issues about the effect of steroids on PCNSLs that were uncontrolled in our study, such as the dose and the time interval between administration and tissue collection. Second, there were distinct disadvantages associated with sampling errors from the use of small tissue samples, even if many of the variables had been controlled. Functional measurements with CT, MRI, or PET would allow serial studies of BBB permeability of the entire tumor over time, which is not possible with tissue sampling. Given the uncommon 


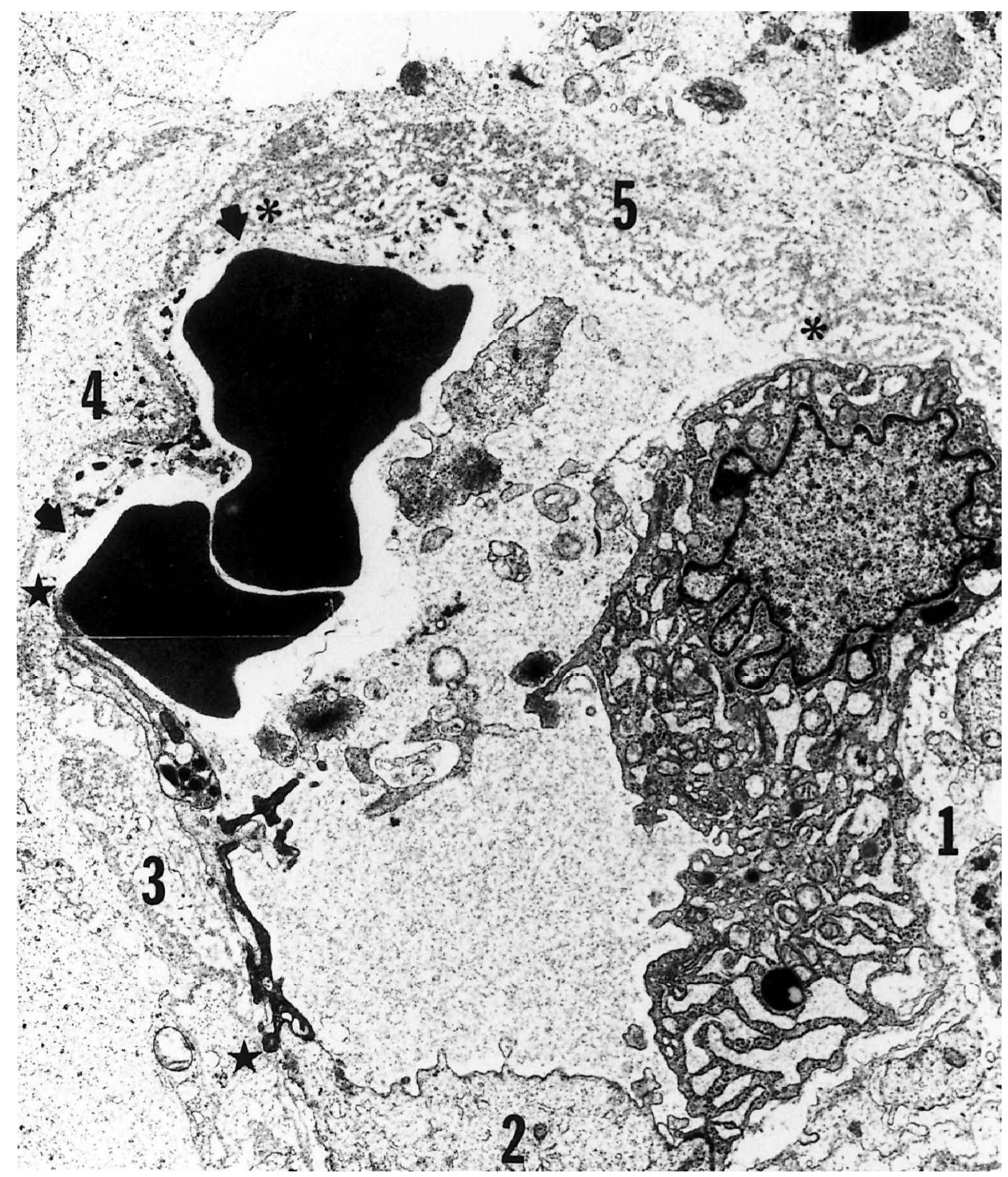

Fig. 8. Capillary or postcapillary venule in a primary CNS lymphoma. Endothelial cells surround an irregular lumen containing two red blood cells. An endothelial cell (1) exhibits early-stage apoptosis, with deep nuclear infoldings and marginated chromatin. The cytoplasm contains a labyrinth of dilated cisternae (rough endoplasmic reticulum ) and a phagolysosome. A cuboidal, light endothelial cell is present (2) as are fragments of as many as 3 endothelial cells (3-4). Continuing clockwise are attenuated, dense, shrunken fragments of endothelial cells (4-5). In wall segment 3 , between the two stars $(\mathrm{H})$, the endothelial cell is shrunken, dense, and may consist of 3 or 4 fragments. In wall segment 4 , between the 2 arrows, only small dense fragments of the endothelial cell remain. In wall segment 5 , between the 2 asterisks $\left({ }^{*}\right)$, there is a large gap with no endothelial cell between the lumen and the basal lamina (montage of 2 electron micrographs $\times 9,800$ ).

occurrence of PCNSLs, a prospective study of BBB function holds the most promise for determining the relationship between steroid administration and the ghost tumor phenomenon in PCNSL.

\section{Acknowledgments}

We acknowledge the technical assistance of Patrick Redden and Edward Maier.

\section{References}

Asher, E., Payne, C.M., and Bernstein, C. (1995) Evaluation of cell death in EBV-transformed lymphocytes using agarose gel electrophoresis, light microscopy and electron microscopy. II. Induction of non-classic apoptosis ("Para-apoptosis") by tritiated thymidine. Leuk. Lymphoma 19, 107-119.
Bashir, R., Chamberlain, M., Ruby, E., and Hochberg, F.H.(1996). T-cell infiltration of primary CNS lymphoma. Neurology 46, 440-444.

Bellamy, C.O.C., Malcomson, R.D.G., Harrison, D.J., and Wyllie, A.H. (1995) Cell death in health and disease: The biology and regulation of apoptosis. Semin. Cancer Biol. 6, 3-16. 
Benharroch, D., Prinsloo, I., Goldstein, J., Brousset, P., Kachko, L., and Gopas, J.U.P. (1996) A comparison of distinct modes of tumor cell death in Hodgkin's disease using morphology and in situ DNA fragmentation. Ultrastruct. Pathol. 20, 497-507.

Bertossi, M., Virgintino, D., Maiorano, E., Occhiogrosso, M., and Roncali, L. (1997) Ultrastructural and morphometric investigation of human brain capillaries in normal and peritumoral tissues. Ultrastruct. Pathol. 21, 41-49.

Burger, P.C., and Scheithauer, B.W. (1994) Tumors of the central nervous system. In: Rosai, J. (Ed.) Atlas of Tumor Pathology, Third series, Fascicle 10. Washington, D.C.: Armed Forces Institute of Pathology.

Cheville, N.F. (1994) Ultrastructural Pathology. An Introduction to Interpretation. Ames, IA: lowa State University Press.

Clarke, P.G.H. (1990) Developmental cell death: Morphological diversity and multiple mechanisms. Anat. Embryol. (Berl.) 181, 195-213.

Collins, J.A., Schandl, C.A., Young, K.K., Vesely, J., and Willingham, M.C. (1997) Major DNA fragmentation is a late event in apoptosis. J. Histochem. Cytochem. 45, 923-934.

Corn, B.W., Marcus, S.M., Topham, A., Hauck, W., and Curran, W.J., Jr. (1997) Will primary central nervous system lymphoma be the most frequent brain tumor diagnosed in year 2000? Cancer 79, 2409-2413.

Cory, S. (1995) Regulation of lymphocyte survival by the bcl 2 gene family. Annu. Rev. Immunol. 13, 513-43.

Crisby, M., Kallin, B., Thyberg, J., Zhivotovsky, B., Orrenius, S., Kostulas, V., and Nilsson, J. (1997) Cell death in human atherosclerotic plaques involves both oncosis and apoptosis. Atherosclerosis 130, 17-27.

Cummings, M.C., Winterford, C.M., and Walker, N.I. (1997) Apoptosis. Am. J. Surg. Pathol. 21, 88-101.

DeAngelis, L.M. (1993) Cerebral lymphoma presenting as a nonenhancing lesion on computed tomographic/magnetic resonance scan. Ann. Neurol. 33, 308-311.

Distelhorst, C.W., and Dubyak, G. (1998) Role of calcium in glucocorticosteroid-induced apoptosis of thymocytes and lymphoma cells: Resurrection of old theories by new findings. Blood 91, 731-734.

Grant, J.W., and Isaacson, P.G. (1992) Primary central nervous system lymphoma. Brain Pathol. 2, 97-109.

Haudenschild, C.C., and Schwartz, S.M. (1979) Endothelial regeneration. II. Restitution of endothelial continuity. Lab. Invest. 41, 407-418.

Hirano, A., Ghatak, N.R., Becker, N.H., and Zimmerman, H.M. (1974) A comparison of the fine structure of small blood vessels in intracranial and retroperitoneal malignant lymphomas. Acta Neuropathol. (Berl.) 27, 93-104.

Honma, T., and Hamasaki, T. (1996) Ultrastructure of multinucleated giant cell apoptosis in foreign-body granuloma. Virchows Archiv. 428, 165-176.

Kahaleh, M.B., Smith, E.A. Soma, Y., and LeRoy, E.C. (1988) Effect of lymphotoxin and tumor necrosis factor on endothelial and connective tissue cell growth and function. Clin. Immunol. Immunopathol. 49, 261-272.

Kaufmann, S.H. (1997) Apoptosis. Pharmacological and Therapeutic Opportunities. San Diego, CA: Academic Press.

Kobayashi, T., Shibuya, N., Yoshida, J., Kagemaya, N., Usui, K., Hara, M., Hirota, T., and Suchi, T. (1983) Malignant intracranial lymphoma - clinical and patho-immunological study. No Shinkei Geka 11, 917-924.

Lo, A.C., Houenou, L.J., and Oppenheim, R.W. (1995) Apoptosis in the nervous system: Morphological features, methods, pathology, and prevention. Arch. Histol. Cytol. 58, 139-149.

Lorenzen, J., Thiele, J., and Fischer, R. (1997) The mummified Hodgkin cell: Cell death in Hodgkin's disease. J. Pathol. 182, 288-298.

Madigan, M.C., and Penfold, P.L. (1997) Human retinoblastoma: A morphological study of apoptotic, leukocytic, and vascular elements. Ultrastruct. Pathol. 21, 95-107.

Maier, J.A.M., Morelli, D., Ménard, S., Colnaghi, M.I., and Balsari, A. (1996) Tumor-necrosis-factor-induced fibroblast growth factor- 1 acts as a survival factor in a transformed endothelial cell line. Am. J. Pathol. 149, 945-952.

Majno, G., and Joris, I. (1995) Apoptosis, oncosis, and necrosis. An overview of cell death. Am. J. Pathol. 146, 3-15.

Mantovani, A., Bussolino, F., and Introna, M. (1997) Cytokine regulation of endothelial cell function: From molecular level to the bedside. Immunol. Today 18, 231-240.

Merrill, J.E., and Benveniste, E.N. (1996) Cytokines in inflammatory brain lesions: Helpful and harmful. Trends Neurosci. 19, 331-338.

Morgello, S. (1995) Pathogenesis and classification of primary central nervous system lymphoma: An update. Brain Pathol. 5, 383-393.

Negri, C., Donzelli, M., Bernardi, R., Rossi, L., Burkle, A., and Scovassi, A.I. (1997) Multiparametric staining to identify apoptotic human cells. Exp. Cell Res. 234, 174-177.

Neuwelt, E.A., Gumerlock, M.K., and Dahlborg, S.A. (1990) Lymphomas of the brain in adults. In: Youmans, J.R. (Ed.) Neurological Surgery, Vol. 5, Third edition. Philadelphia:W.B. Saunders. pp. 3137-3151.

Ochi, A., Shibata, S., and Mori, K. (1989) Ultrastructure of capillary permeability in malignant lymphoma. No Shinkei Geka 17, 1139-1143.

Ott, R.J., Brada, M., Flower, M.A., Babich, J.W., Cherry, S.R., and Deehan, B.J. (1991) Measurements of blood-brain barrier permeability in patients undergoing radiotherapy and chemotherapy for primary cerebral lymphoma. Eur. J. Cancer 27, 1356-1361.

Piris, M.A., Pezzella, F., Martinez-Montero, J.C., Orradre, J.L., Villuendas, R., Sanchez-Beato, M., Cuena, R., Cruz, M.A., Martinez, B., Garrido, M.C., Gatter, K., Aiello, A., Delia, D., Giardini, R., and Rilke, F. (1994) p53 and bcl-2 expression in high-grade B-cell lymphomas: Correlation with survival time. Br. J. Cancer 69, 337-341.

Pirotte, B., Levivier, M., Goldman, S., Brucher, J.-M., Brotchi, J., and Hildebrand, J. (1997) Glucocorticoid-induced long-term remission in primary cerebral lymphoma: Case report and review of the literature. J. Neurooncol. 32, 63-69.

Pistoia, V. (1997) Production of cytokines by human B cells in health and disease. Immunol. Today 18, 343-350.

Plowman, P.N., and Wise, R.J. (1984) Intracerebral lymphoma deposits: Investigation and treatment. Int. J. Rad. Oncol. Biol. Phys. 10, 843-849.

Polunovsky, V.A., Wendt, C.H., Ingbar, D.H., Peterson, M.S., and Bitterman, P.B. (1994) Induction of endothelial cell apoptosis by TNF alpha: Modulation by inhibitors of protein synthesis. Exp. Cell Res. 214, 584-594.

Portera-Cailliau, C., Price, D.L., and Martin, L.J. (1997) Excitotoxic neuronal death in the immature brain is an apoptosis-necrosis morphological continuum. J. Comp. Neurol. 378, 70-87.

Regan, R.F., Panter, S.S., Witz, A., and Tilly, J.L. (1995) Ultrastructure of excitotoxic neuronal death in murine cortical culture. Brain Res. 705 , 188-198.

Reidy, M.A., and Schwartz, S.M. (1981) Endothelial regeneration. III. Time course of intimal changes after small defined injury to rat aortic endothelium. Lab. Invest. 44, 301-308.

Reidy, M.A., and Schwartz, S.M. (1983) Endothelial injury and regeneration. IV. Endotoxin: A nondenuding injury to aortic endothelium. Lab. Invest. 48, 25-34.

Romero, L.I., Zhang, D.-N., Herron, G.S., and Karasek, M.A. (1997) Interleukin-1 induces major phenotypic changes in human skin microvascular endothelial cells. J. Cell. Physiol. 173, 84-92.

Rojiani, A.M., and Dorovini-Zis, K. (1996) Glomeruloid vascular structures in glioblastoma multiforme: An immunohistochemical and ultrastructural study. J. Neurosurg. 85, 1078-1084.

Roy, S., and Sarkar, C. (1989) Ultrastructural study of micro-blood vessels in human brain tumors and peritumoral tissue. J. Neurooncol. 7, 283-294.

Savill, J. (1994) Apoptosis in disease. Eur. J. Clin. Invest. 24, 715-723.

Shibata, S. (1989) Ultrastructure of capillary walls in human brain tumors. Acta Neuropathol. 78, 561-571.

Schulte-Herman, N.R., Bursch, W., Grasl-Kraupp, B., Marian, B., Kahl-Rainer, 
P., and Ellinger, A.T.P. (1997) Concepts of cell death and application to carcinogenesis. Toxicol. Pathol. 25, 89-93.

Schwartz, L.M. (1995) The faces of death. Cell Death Differ. 2, 83-85.

Schwartz, S.M., Haudenschild, C.C., and Eddy, E.M. (1978) Endothelial regeneration. I. Quantitative analysis of initial stages of endothelial regeneration in rat aortic intima. Lab. Invest. 38, 568-580.

Sgonc, R., and Wick, G. (1994) Methods for the detection of apoptosis. Int. Arch. Allergy Immunol. 105, 327-332.

Slowik, M.R., Min, W., Ardito, T., Karsan, A., Kashgarian, M., and Pober, J.S. (1997) Evidence that tumor necrosis factor triggers apoptosis in human endothelial cells by interleukin-1-converting enzyme-like protease-dependent and -independent pathways. Lab. Invest. 77, 257-267.

Tellez, C., VonRoenn, J., and Levy, R.M. (1997) Neoplasms of the central nervous system in acquired immunodeficiency syndrome. In: Berger, J.R., and Levy, R.M. (Eds.), AIDS and the Nervous System. Second edition. New York: Lippincott-Raven. pp. 705-720.
Tomlinson, F.H., Kurtin, P.J., Suman, V.J., Scheithauer, B.W., O'Fallon, J.R., Kelly, P.J., Jack, C.R., Jr., and O'Neill, B.P. (1995) Primary intracerebral malignant lymphoma: A clinicopathological study of 89 patients. J. Neurosurg. 82, 558-566.

Trump, B.F., Berezesky, I.K., Chang, S.H., and Phelps, P.C. (1997) The pathways of cell death: Oncosis, apoptosis, and necrosis. Toxicol. Pathol. 25, $82-88$.

Tsai, E.Y., Yie, J., Thanos, D., and Goldfeld, A.E. (1996) Cell-type-specific regulation of the human tumor necrosis factor alpha gene in B cells and $T$ cells by NFATp and ATF-2/Jun. Mol. Cell. Biol. 16, 5232-5244.

Ueda, F., Takashima, T., Suzuki, M., Kadoya, M., Yamashita, J., and Kida, T. (1995) MR imaging of primary intracranial malignant lymphoma. Radiat. Med. 13, 51-57.

Vaquero, J., Martinez, R., Rossi, E., and Lopez, R. (1984) Primary cerebral lymphoma: The "ghost tumor." J. Neurosurg. 60, 174-176.

Wyllie, A.H. (1997) Apoptosis. An overview. Br. Med. Bull. 53, 451-685. 